\title{
Internal Friction Behavior Associated with Martensitic Decomposition in Low-carbon Dual-phase Steel
}

\author{
Jinfeng ZHANG ${ }^{1,2)}$ Xiaochun WU, ${ }^{1)}$ Na MIN, ${ }^{1)}$ Shungui ZUO ${ }^{3)}$ and Mingjiang $\mathrm{JIN}^{3 / *}$ \\ 1) State Key Laboratory of Advanced Special Steel \& Shanghai Key Laboratory of Advanced Ferrometallurgy \& School of Mate- \\ rials Science and Engineering, Shanghai University, Shanghai, 200444 China. \\ 2) School of Electronic and Information Engineering, Suzhou Vocational University, Suzhou, 215104 China. \\ 3) Institute of Phase Transformation and Complex Structure, School of Materials Science and Engineering, Shanghai Jiao \\ Tong University, Shanghai, 200240 China.
}

(Received on November 1, 2018; accepted on February 5, 2019; J-STAGE Advance published date: May 18, 2019)

\begin{abstract}
In this study, the martensitic decomposition behaviors of a low-carbon dual-phase steel were investigated by the low-frequency internal friction method, combined with various structural analysis techniques including X-ray diffraction, scanning electron microscopy, and transmission electron microscopy. Two internal friction peaks were observed at $418.4^{\circ} \mathrm{C}$ and $448.1^{\circ} \mathrm{C}$, and were attributed to desolventization of supersaturated carbon atoms from martensite and formation of $\mathrm{Cr} 3 \mathrm{C} 7$ precipitates, respectively. The results indicated that the two-step process during the martensitic decomposition, involving carbon atom diffusion and carbide precipitation, could be well explained by the internal friction technique. The microstructural mechanisms associated with the generation of the two internal friction peaks during the martensitic decomposition are discussed.
\end{abstract}

KEY WORDS: DP steel; internal friction; martensitic decomposition.

\section{Introduction}

Advanced high-strength steels, such as dual-phase (DP), transformation-induced plasticity (TRIP), and martensitic steels, have been developed and widely used in the automobile industry. ${ }^{1-3)}$ Phenomena such as carbon segregation to structural defects, carbide precipitation in martensite or bainite, carbon partitioning from martensite to austenite during quenching, partitioning, and tempering involve carbon diffusion in a supersaturated matrix. ${ }^{4,5)}$ However, the measurement of carbon diffusivity in steels is still very challenging.

Internal friction (IF) technique has been proved as an effective approach to study the microstructural evolution, defects characteristics, or phase transformations inside the metal materials. ${ }^{6-9)}$ For steels, an IF measurement with a high sensitivity could be utilized to characterize the interstitial or dissolved carbon atoms in body-centered cubic (BCC) structural phases such as ferrite and martensite phases. Some typical internal friction peaks observed in steels include the Snoek peak, the Snoek-Köster peak ${ }^{10)}$ and the spurious peak induced by reduction of background internal friction, and so on. Such internal friction characteristics have been verified related with various occupation or movement behavior of the carbon atoms. Therefore, this suggests that the IF technique can be also used to investigate other

\footnotetext{
* Corresponding author: E-mail: jinmj@sjtu.edu.cn

DOI: https://doi.org/10.2355/isijinternational.ISIJINT-2018-718
}

structural evolutions associated with movements of carbon atoms in steels.

Extensive studies are ongoing to understand the martensitic decomposition behaviors and associated mechanisms, which could be potentially utilized to advance the methods of precise microstructure control of steels. In this study, we investigated the IF behaviors accompanying the martensitic decomposition and carbide precipitation in DP steels, and discuss the underlying mechanisms.

\section{Experimental}

A low-carbon martensitic DP automobile steel was used in this study. Its chemical composition expressed by mass fractions is: $0.081 \% \mathrm{C}, 0.0419 \% \mathrm{Si}, 1.88 \% \mathrm{Mn}, 0.0124 \%$ $\mathrm{S}, 0.03 \% \mathrm{P}$, and $0.278 \% \mathrm{Cr}$. The initial volume fraction of martensite is approximately $25 \%$, while the other volume fraction corresponds to ferrite.

The mechanical spectrum was measured using an FTA700 low-frequency IF tester (Kê torsion pendulum) in the free-attenuation mode. The measurements were performed at a heating rate of $2^{\circ} \mathrm{C} \cdot \mathrm{min}-1$, strain amplitude of $4.8 \times$ $10^{-5}$, and atmosphere pressure of $6 \times 10^{-2} \mathrm{~Pa}$. Standard specimens with thicknesses, widths, and lengths of 1,3 , and $55 \mathrm{~mm}$, respectively, were cut by a slow-feeding wire-cut machine. The specimens were then abraded and polished with a metallographic abrasive paper, followed by application of $4 \%$ nitric acid/ethanol to corrode their surfaces.

The attenuation degree of the specimen's amplitude was 
used to calculate the IF using a Kê torsion pendulum. In order to improve the measurement accuracy, the system measures several free-attenuation vibration cycles and calculates the logarithmic mean value of the amplitude to determine the IF: ${ }^{11-13)}$

$$
Q^{-1}=\delta / \pi=1 /(\pi \cdot m) \ln \left(A_{n} / A_{n+m}\right),(\delta<<1) \ldots \ldots
$$

where $m$ is the number of continuous vibration waves, $A_{n}$ is the amplitude of the $n^{\text {th }}$ vibration, $A_{n+m}$ is the amplitude of the $(\mathrm{n}+\mathrm{m})^{\text {th }}$ vibration, and $\delta$ is the natural-logarithm ratio of $A_{n}$ to $A_{n+m}$.

The increase in temperature generally leads to larger distances between atoms and smaller binding forces between them, yielding a smaller modulus. The specimen's lower end is held by the lower chuck of the torsion pendulum of the low-frequency inverted-torsional IF tester, whereas the other end of the specimen is connected to the rod of the inverted pendulum so that it can freely rotate. Therefore, the modulus recorded in the IF test reflects the specimen's shear modulus, which is proportional to the square of the vibrational frequency of the torsion pendulum: ${ }^{14}$

$$
G=8 \pi l I f^{2} / R^{4}
$$

Where $\mathrm{I}$ is the moment of inertia of the torsional pendulum, 1 is the specimen effective length, $\mathrm{R}$ is the specimen radius, approximately equal to $\sqrt{a^{2}+b^{2}} / 2$ (a is the specimen's width, $b$ is the specimen's thickness), and $\mathrm{f}$ is the resonance frequency of the torsional pendulum.

The evolutions of the thermophysical properties were measured at a heating rate of $2^{\circ} \mathrm{C} \cdot \mathrm{min}-1$ by differential scanning calorimetry (DSC, PE DSC-8000) and thermal expansion analysis (NETZSCHDIL 402 Expedis Classic). The phase structure of the specimen was analyzed by means of X-ray diffraction (SHIMADZU XRD-7000) using $\mathrm{Co} \mathrm{K} \alpha$ radiation. The scanning rate is $2 \% \mathrm{~min}$. In addition, a Hitachi S2570 scanning electron microscope (SEM) was used to observe the metallography structure. A microstructural characterization was performed by transmission electron microscopy (TEM) with a JEOL JEM$2010 \mathrm{~F}$ microscope operated at $200 \mathrm{kV}$. TEM samples were prepared by a twin-jet polisher operated at $30^{\circ} \mathrm{C}$ and $15 \mathrm{~V}$, using a solution of 5\% perchloric acid and 95\% ethanol (expressed in volume percentages). An MTS Exceed 64 tensile tester was used to evaluate the mechanical properties of the specimens.

\section{Results and Discussion}

In order to characterize the martensitic decomposition process, the thermal expansion, heat flow, and mechanical spectrum as a function of the temperature during heating of the studied low-carbon DP steel from room temperature to $500^{\circ} \mathrm{C}$ at a heating rate of $2^{\circ} \mathrm{C} \cdot \mathrm{min}-1$ are analyzed, as shown in Fig. 1. The thermal expansion method is a typical method used to characterize phase transformations in steels. Figure 1(a) shows that the expansivity of the DP steel has a linear evolution during the heating until the temperature reached approximately $455^{\circ} \mathrm{C}$, where a significant decrease is observed. The decrease in the expansivity usually indicates the occurrence of a phase change. In this

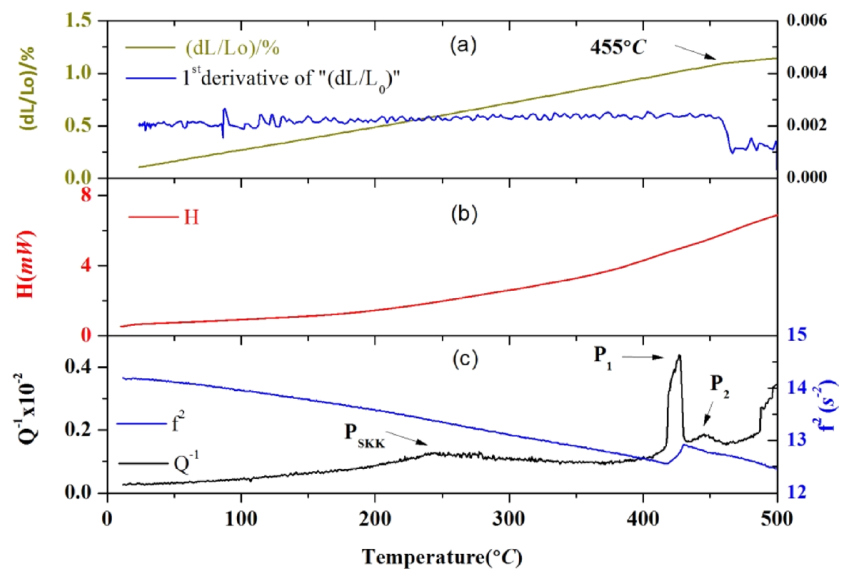

Fig. 1. (a) Thermal expansion, (b) heat flow, and (c) mechanical spectrum of the studied low-carbon DP steel as a function of the temperature during heating from room temperature to $500^{\circ} \mathrm{C}$ at a heating rate of $2^{\circ} \mathrm{C} \cdot \mathrm{min}^{-1}$; the resonance frequency is $3.5 \mathrm{~Hz}$. (Online version in color.)

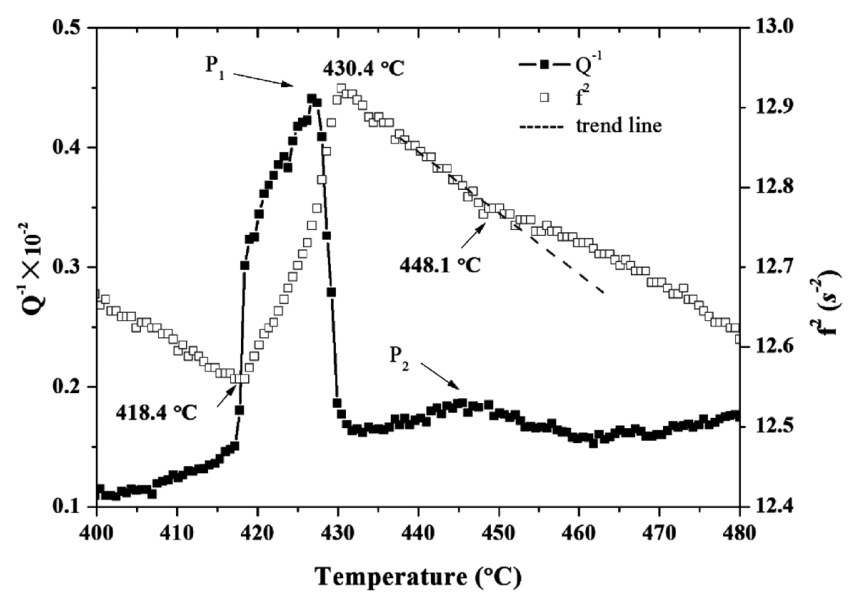

Fig. 2. Regional analysis of the temperature-dependent IF and modulus of the DP steel at the temperature range of 400 to $480^{\circ} \mathrm{C}$.

case, it indicated the martensitic decomposition. DSC is also considered an effective method to study first-order phase transformations of materials by monitoring the latent heat accompanying the transformation. However,no obvious endothermic or exothermic peak can be distinguished from the DSC curve in Fig. 1(b). The mechanical spectra including the IF and shear modulus of the DP steel are shown in Fig. 1(c). Three IF peaks are observed, marked by the arrows. The peak at approximately $250^{\circ} \mathrm{C}$ is believed to be the Snoek-Kê-Köster (SKK) peak, which has been well studied,attributed to movable dislocations interacting with interstitial atoms. ${ }^{15,16)}$ The other two peaks, denoted as P1 and $\mathrm{P} 2$, are located in a narrow temperature range of 400 to $460^{\circ} \mathrm{C}$.

Figure 2 shows the regional analysis of the temperaturedependent IF and modulus of the DP steel in the range of 400 to $480^{\circ} \mathrm{C}$. The IF peak $\mathrm{P}_{1}$ started at approximately $418.4^{\circ} \mathrm{C}$; the peak temperature is approximately $430.4^{\circ} \mathrm{C}$. The peak spectrum is very sharp and irregular. The peak did not match with the Debye law, which is typically valid for a thermal-activity relaxation-type IF peak. The peak $\mathrm{P}_{1}$ was accompanied by an abnormal significant increase in the modulus. These results indicated that the peak is associated 
with a phase transition. The peak spectrum of $\mathrm{P}_{2}$ is also irregular accompanied by modulus changes. The decrease in the temperature-dependent modulus deviates from the linearity; a small increase is observed during the heating beyond the critical temperature of approximately $448.1^{\circ} \mathrm{C}$. The temperature is in agreement with that of the expansivity changes.

Figure 3 shows the results of the IF measurements at the vibration frequencies of 1.1 and $3.5 \mathrm{~Hz}$ at a heating rate of $2{ }^{\circ} \mathrm{C} \cdot \min -1$. The resonant frequency was adjusted by changing the mass and length of the pendulum rod. The temperatures corresponding to the $\mathrm{P}_{1}$ and $\mathrm{P}_{2}$ peaks did not change upon the adjustment of the frequency, which indicates that the positions of both IF peaks are frequency-independent.

Therefore, it can be concluded that the two IF peaks are not relaxation-type peaks, but associated with phase transformations and microstructural evolutions.

Figure 4 shows the IF spectra as a function of the temperature of the DP steel for two thermal cycles, in the range of room temperature to $500^{\circ} \mathrm{C}$. The $\mathrm{P}_{\mathrm{SKK}}, \mathrm{P}_{1}$, and $\mathrm{P}_{2}$ IF peaks observed in the first heating cycle disappeared, while the background IF spectra were significantly reduced. This indicated that the original structure of the DP steel was modified

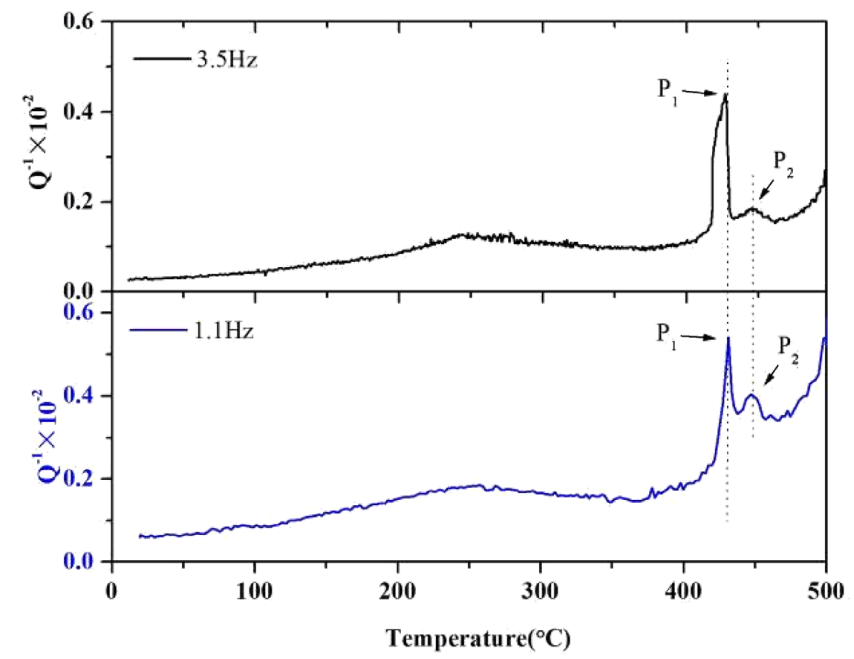

Fig. 3. Temperature-dependent IF patterns of the DP steel during the heating from room temperature to $500^{\circ} \mathrm{C}$ at frequencies of 1.1 and $3.5 \mathrm{~Hz}$. (Online version in color.)

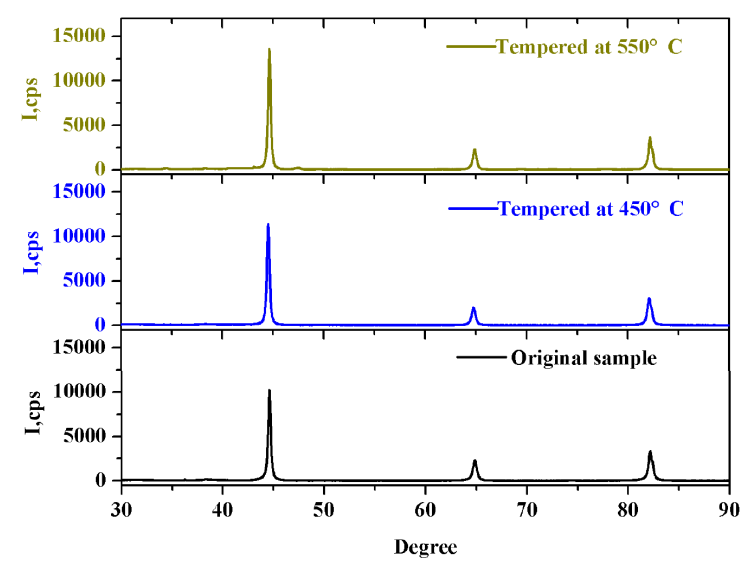

during the first cycle of heating to $500^{\circ} \mathrm{C}$. The disappearance of $\mathrm{P}_{\mathrm{SKK}}$ could be easily explained by the significant decrease in the dislocation density and interstitial carbon atom concentration, likely attributed to the martensitic decomposition or carbide precipitation during the thermal cycle. The reduction in the background IF may be attributed to the decrease in the density of movable dislocations. ${ }^{17,18)}$ In addition, the disappearance of the $\mathrm{P}_{1}$ and $\mathrm{P}_{2}$ IF peaks indicated that the phase transformation and microstructural change during the heating in the first thermal cycle were irreversible.

Therefore, the observed temperature-dependent spectra of both IF and modulus reflect the martensitic decomposition of the DP steel. A further microstructural analysis is performed to reveal the underlying mechanism of the complex IF behaviors.

Figure 5(a) shows the XRD pattern for the DP steel specimen in the initial state and those of the specimens tempered for $20 \mathrm{~min}$ at 450 and $500^{\circ} \mathrm{C}$. The patterns of the as-received DP steel and specimens tempered at 450 and $500^{\circ} \mathrm{C}$ showed the typical single BCC structure of martensite or ferrite. It is typically difficult to distinguish between martensite

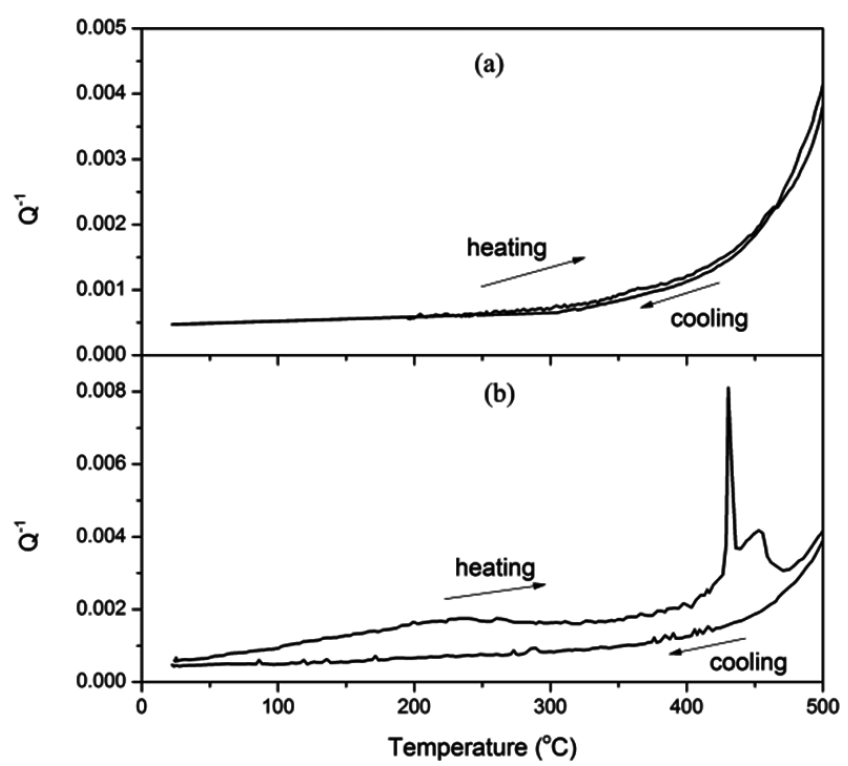

Fig. 4. Temperature-dependent IF patterns of the DP steel in the (a) first and (b) second thermal cycles in the range of room temperature to $500^{\circ} \mathrm{C}$.

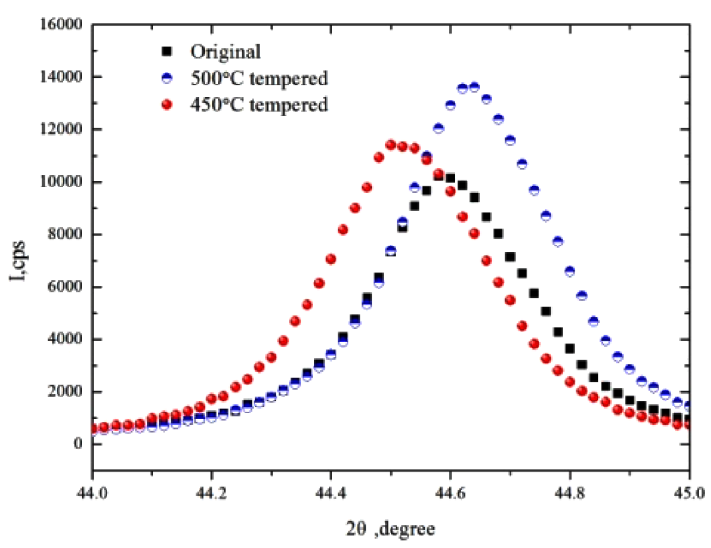

Fig. 5. (a) X-ray diffraction (XRD) patterns of DP steel specimens in the original state, tempered at $450^{\circ} \mathrm{C}$ for $20 \mathrm{~min}$, and tempered at $500^{\circ} \mathrm{C}$ for $20 \mathrm{~min}$, and (b) precise analysis of the evolution of the $\alpha(110)$ peak for the three XRD diffraction patterns. (Online version in color.) 
and ferrite by XRD. A precise analysis of the evolution of the $\alpha$ (110) peak for the three XRD diffraction patterns is presented in Fig. 5(b). The results showed that the $\alpha$ (110) peak is observed at $44.58^{\circ}$ for the original specimen, which decreased to $44.50^{\circ}$ after the tempering at $450^{\circ} \mathrm{C}$, followed by an increase to $44.64^{\circ}$ upon the tempering at $500^{\circ} \mathrm{C}$. According to the Bragg equation from the crystal diffraction theory, the diffraction angle is inversely proportional to the interplanar spacing. Therefore, in this study, the interplanar spacing increased upon the tempering at $450^{\circ} \mathrm{C}$, and then decreased upon the tempering at $500^{\circ} \mathrm{C}$.

The martensitic decomposition in steels is generally described as ordering of the carbon atoms as well as some carbide precipitation under thermal activation. For the DP steel composed of $75 \%$ ferrite and $25 \%$ martensite, the martensitic decomposition involved diffusion of carbon atoms from the carbon-rich martensite to the carbon-lean ferrite and carbide precipitation. The IF peak $\mathrm{P}_{1}$ accompanied with the modulus decrease below $450^{\circ} \mathrm{C}$ is believed to originate from the diffusion of carbon atoms from martensite to ferrite. The non-relaxation-type IF peak is generally associated with the emergence or evolution of the interface during the phase transformation, such as the thermoelastic martensitic transformation in shape memory alloys. ${ }^{19)}$ In this study, it may be attributed to the interface migration upon the martensitic decomposition. Meanwhile, upon the migration of the carbon atoms into ferrite, the macroscopic lattice constant increased, as shown in the XRD pattern. This led to decreases in the density and modulus.

When the specimen was heated to the higher temperature, the carbon atoms in the matrix started to desolventize and form the carbide precipitates; in addition, the number of dissolved carbon atoms in the matrix rapidly decreased. This well explains the significant decrease in the lattice constant of the specimen tempered at $500^{\circ} \mathrm{C}$. With this process, we observed an irregular so-called IF peak $\mathrm{P}_{2}$ accompanied with a slight increase in the modulus. However, the mechanism of the mechanical spectroscopy associated with precipitation transformation in steels or alloys is unclear yet. For carbon steels, a reasonable explanation is the presence of an internal friction athermal background that generated by the interaction of dislocations with point defects situated away from the dislocations glide plane. ${ }^{20,21)}$ This background is proportional to carbon content in solid solution, and decreases due to the precipitation of carbides, producing a curve with a peak shape. ${ }^{22)}$ In this study, the IF spectrum of the DP steel during cooling showed that the background of the IF spectrum significantly decreased after the thermal cycle. Additionally, a slight increase in the modulus accompanied this process. These results strongly support our conclusions that $\mathrm{P}_{2}$ is not a peak, but a local maximum or shoulder caused by the reduction in the background of the mechanical spectrum.

A microstructural observation and mechanical analysis were carried out to provide more intuitive evidences for these phenomena.

Figure 6 shows the morphologies of the original specimen and two tempered DP steel specimens measured by SEM. A typical metallographic structure of the martensite/ ferrite DP steel was observed in the as-received specimen, in which martensite exhibits an island-like distribution in the ferrite matrix. The size of the martensite bulk is in the range of 1 to $15 \mu \mathrm{m}$. The clear edges and smooth surface of the martensite/ferrite interface are shown in Fig. 6(a). After the tempering at $450^{\circ} \mathrm{C}$ for $20 \mathrm{~min}$, the morphology of the DP steel specimen was considerably changed. Although the original martensite/ferrite interface can be still resolved, the interface is not smooth and the martensite bulk is not clearly distinguishable. This indicates that the interface migration occurred during the martensitic decomposition in the DP steel tempered at $450^{\circ} \mathrm{C}$, according to the observed structural evolution behaviors. As mentioned above, a phasetransformation IF peak is generally associated with interface generation or movement. This well explains that the $\mathrm{P}_{1}$ IF peak emerges by the migration of the original martensite/ ferrite interfaces.

Figure 7 shows representative TEM micrographs of the DP steel specimens that tempered at $450^{\circ} \mathrm{C}$ (a) and $500^{\circ} \mathrm{C}$ (b-c) for $20 \mathrm{~min}$, respectively. The area with a higher density of dislocations corresponds to martensite, while the other area corresponds to ferrite. After the tempering, a considerable number of dislocations are still observed in the martensite phase. A part of the martensite/ferrite interface was modified and became unclear and rough for both specimens, as shown in the bright-field images in Figs. 7(a) and $7(\mathrm{~b})$. This further confirms the previous results about the interface migration. The diffraction pattern on the martensite phase of the specimen tempered at $450^{\circ} \mathrm{C}$ is marked as a single BCC phase. However, the diffraction pattern of
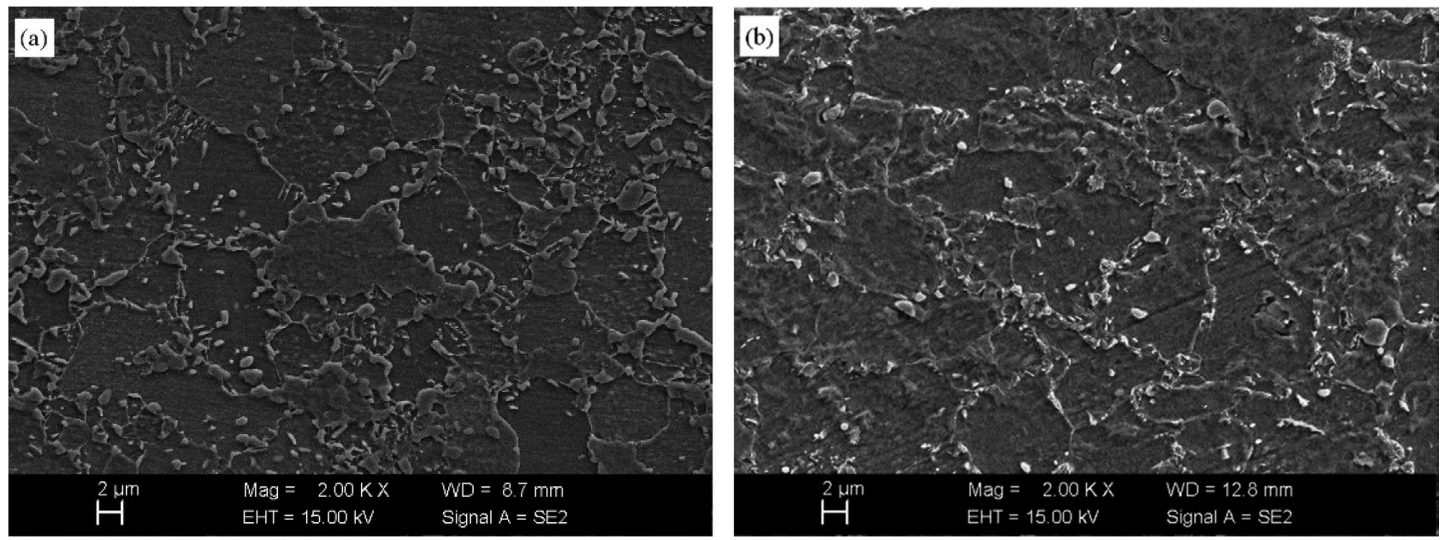

Fig. 6. SEM images of the DP steel morphologies for the specimens in the (a) original state and (b) tempered at $450{ }^{\circ} \mathrm{C}$ for $20 \mathrm{~min}$. 

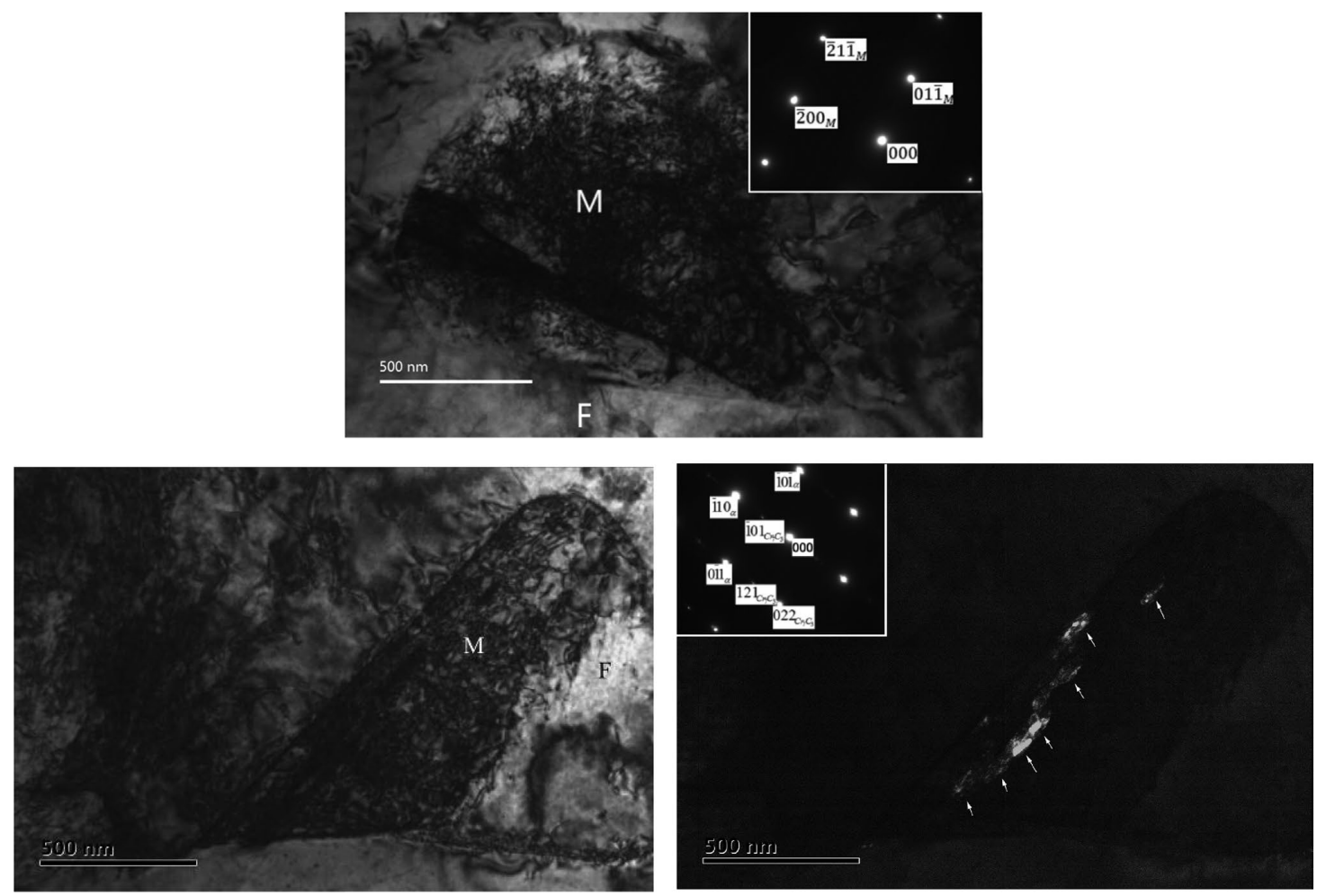

Fig. 7. TEM images of the tempered DP steel: (a) bright-field micrographs of specimen tempered at $450^{\circ} \mathrm{C}$ for $20 \mathrm{~min}$ with the martensite and ferrite and the corresponding selected-area electron diffraction (SAED) patterns showing a single bcc phase, (b) bright-field micrographs of specimen tempered at $500^{\circ} \mathrm{C}$ for $20 \mathrm{~min}$ and (c) dark-field micrographs showing the precipitates $\left(\mathrm{Cr}_{7} \mathrm{C}_{3}\right)$ and the corresponding SAED patterns.

the specimen tempered at $500^{\circ} \mathrm{C}$ is different that a second phase was clearly observed. The analysis of the diffraction spots showed the presence of a second phase around the martensite/ferrite interface. A few granular features were observed in the corresponding dark-field image in Fig. 7(c). The composition of the second phase can not be intuitively characterized by EDS technique due to the ferromagnetism of the specimen. So the precipitate phase were inferred from two criteria: one is the orientation relationship between the precipitate and the martensite matrix as well as the lattice constants obtained from the diffraction spot. After calibration, the results reveal that the new phase most likely corresponds to the $\mathrm{Cr}_{7} \mathrm{C}_{3}$ precipitates. The second one is from the reference, ${ }^{23-25}$ in which it was mentioned that the formation temperature of the microalloyed $\mathrm{Cr}_{7} \mathrm{C}_{3}$ carbides in steel is around $550^{\circ} \mathrm{C}$. It is close to the experimental results in our case. According to the alloy composition of the DP steel in this study, we inferred that the precipitates formed at $500^{\circ} \mathrm{C}$ is the $\mathrm{Cr}_{7} \mathrm{C}_{3}$ phase. As we checked that no precipitates could be distinguished even after aging at $450^{\circ} \mathrm{C}$, it indicated that the $\mathrm{Cr}_{7} \mathrm{C}_{3}$ carbides precipitated during the tempering at $500^{\circ} \mathrm{C}$, which is characterized by the appearance of the so-called $\mathrm{P}_{2}$ IF peak and relative increase in the modulus.

Figure 8 shows the mechanical properties of the original DP steel specimen and tempered specimens. The as-received DP steel exhibits a lower yield stress, continuous yielding, and increased strain hardening rate, which is consistent with the typical mechanical stress-strain curve of the martensite/ ferrite DP steel. The DP steel usually consists of hard martensite islands embedded in a soft ferrite matrix, leading to a relatively high ultimate tensile strength (UTS), low yield-to-tensile-strength ratio, absence of yield point elon-

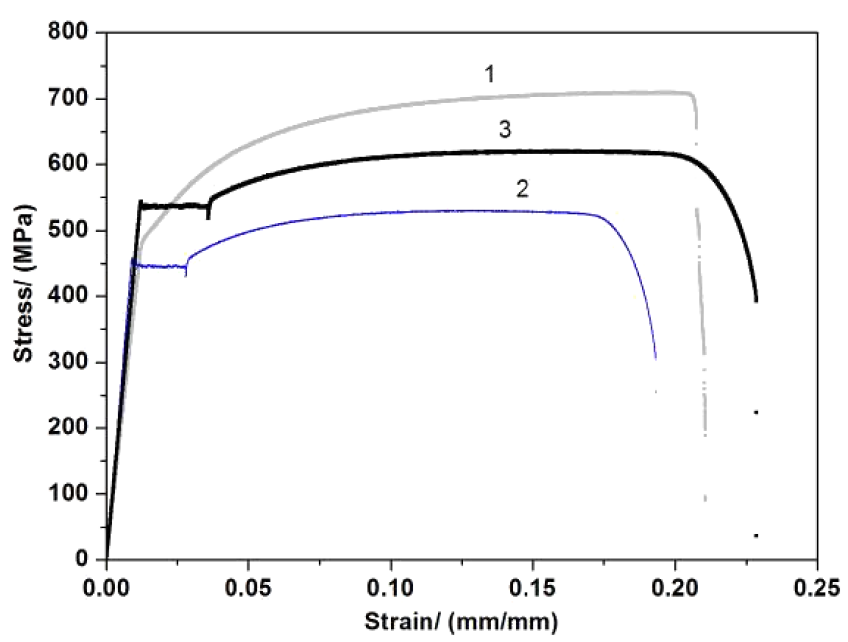

Fig. 8. Tensile properties of the DP steel specimens: original state denoted as 1 , specimen tempered at $450^{\circ} \mathrm{C}$ for $20 \mathrm{~min}$, denoted as 2 , and specimen tempered at $500^{\circ} \mathrm{C}$ for $20 \mathrm{~min}$, denoted as 3. (Online version in color.)

gation, and good balance of strength and formability. After the specimens were tempered, the strain-dependent stress significantly changed so that a yield platform was observed followed by the strengthening segment of reinforcement. For the specimen tempered at $450^{\circ} \mathrm{C}$, the yield strength was approximately $457.5 \mathrm{MPa}$, similar to that of the as-received DP steel. Upon the tempering at $500^{\circ} \mathrm{C}$, the yield strength increased to approximately $543.1 \mathrm{MPa}$, which is an increase of approximately $18.7 \%$. The yield strength of may lie on the ferrite structure, which acts as the soft phase in the DP steels. This indicates that the ferrite structure did not significantly change, although the structural characteristics of 
the martensite/ferrite DP structure were destroyed and the number of solid-solution carbon atoms in the ferrite phase increased after the tempering at $450^{\circ} \mathrm{C}$. After the tempering at $500^{\circ} \mathrm{C}$, the carbides were precipitated in the ferrite phase and led to a significant increase in the yield strength.

In general, the evolutions of the mechanical properties of the original DP steel and tempered specimens further confirm the two processes in the martensitic decomposition: carbon atom diffusion from martensite to ferrite and carbide precipitation. These two processes are reflected by the two peaks, $\mathrm{P}_{1}$ and $\mathrm{P}_{2}$, observed in the IF spectrum of the DP steel during the heating.

\section{Conclusions}

This study showed that the IF technique combined with the microstructural analysis has a very unique advantage in the characterization of structural evolution or phase transitions related to the movement of carbon atoms. Compared to the traditional testing technologies, such as thermal analysis (DSC) and thermal expansion, the IF measurement could provide more information for the characterization of the martensitic decomposition of the DP steel. It will be of significance to further develop the spectrum analysis technique and analyze the IF physical mechanisms to understand the phase transitions or structural evolutions associated with carbon atom movements in steels.

In this study, the martensitic decomposition behaviors of the low-carbon DP steel were studied by the low-frequency IF method, combined with XRD, SEM, and TEM analyses. Two IF peaks associated with the martensitic decomposition were observed at 430.4 and $448.1^{\circ} \mathrm{C}$. The lower-temperature peak was attributed to the migration of the martensite/ferrite interface as the supersaturated carbon atoms moved from martensite to ferrite, while the higher-temperature peak was attributed to the formation of the $\mathrm{Cr}_{3} \mathrm{C}_{7}$ precipitates. This indicates that both carbon atom diffusion and carbide precipitation, i.e., the two-step process of the martensitic decomposition, can be well described by the IF technique. The related mechanisms of the phase transition and microstructural evolution during the martensitic decomposition were also explained.

\section{Acknowledgement}

This work was supported by the National Key Research and Development Program of China (Program Number: 2016YFB0300400) and the Suzhou Vocational University Foundation for Research (Grant No. SVU2016YY03). The author would like to thank Prof. Shen Zhongcheng and Mr. Lan Jinshan (Suzhou Siyuan material Measurement Technology Institute), and the Institute of Solid State Physics, Chinese Academy of Sciences for the supports in measuring the internal friction spectra and appreciate the valuable advice from Prof. L. B. Magalas (AGH University of Science, Poland).

\section{REFERENCES}

1) M. T. Ma and B. R. Wu: Dual Phase Steel Physical and Mechanical Metallurgy, Metallurgical Industry Press, Beijing, (2009), 1.

2) E. V. Pereloma, M. K. Miller and I. B. TimokhinaI: Metall. Mater. Trans. A, 39 (2008), 3210.

3) S. J. Kim, Y. G. Cho, C. S. Oh, E. K. Dong, B. M. Man and N. H. Heung: Mater. Des., 30 (2009), 1251.

4) P. C. Chen and P. G. Winchell: Metall. Mater. Trans. A, 11 (1980), 1333.

5) E. M. Grinberg and A. A. Alekseev: Met. Sci. Heat Treat., 59 (2017), 1.

6) M. Mehdizadeh and M. M. Khonsari: Int. J. Fatigue, 114 (2018), 159.

7) J. J. Hoyos, H. R. Salva, J. M. Vélez and A. A. Ghilarducci: Mater. Sci. Eng. A, 660 (2016), 148.

8) M. Preciado and M. Pellizzari: J. Mater. Sci., 49 (2014), 8183.

9) S. Li, L. Deng, X. Wu, H. Wang and Y. Min: Mater. Sci. Eng. A, 527 (2010), 6899.

10) L. Magalas: Acta Metall. Sin., 39 (2003), 1145

11) X. F. Zhu and J. P. Shui: Acta Phys. Sin., 45 (1996), 1010

12) A. S. Nowick and B. S. Berry: Anelastic Relaxation in Crystalline Solids, Academic Press, London, (1972), 20.

13) L. B. Magalas and A. Stanislawczyk: Key Eng. Mater., 319 (2006), 231.

14) Z. S. Li, Q. F. Fang, S. Veprek and S. Z. Li: Rev. Sci. Instrum., 74 (2003), 2477.

15) X. Lu, H. Liu and X. Jin: J. Alloy. Compd., 577 (2013), 72.

16) S. Li, N. Min, J. Li, X. Wu, C. Li and L. Tang: Mater. Sci. Eng. A, 575 (2013), 51.

17) R. Bagramov, D. Mari and W. Benoit: Philos. Mag. A, 81 (2001), 2797.

18) R. Martin, I. Tkalcec, D. Mari and R. Schaller: Philos. Mag. A, 88 (2008), 2907.

19) J. S. Juan and M. L. No: J. Alloy. Compd., 355 (2003), 65.

20) J. J. Hoyos, A. Ghilarducci, H. Salva and J. Vélez: Solid State Phenom., 184 (2012), 221.

21) I. Tkalcec, D. Mari and W. Benoit: Mater. Sci. Eng. A, 442 (2006), 471.

22) J. J. Hoyos, A. A. Ghilarducci and D. Mari: Mater. Sci. Eng. A, 640 (2015), 460.

23) S. Li, X. Xi, Y. Luo, M. Mao, X. Shi, J. Guo and H. Guo: Materials, 11 (2018), 2491

24) A. Fava, R. Montanari and A. Varone: Metals, 8 (2018), 870.

25) G. R. Speich and W. C. Leslie: Metall. Trans., 3 (1972), 1043. 